\title{
Carbon Nanotubes With Different Orientations for Electrochemical Biodevices
}

\author{
Irene Taurino, Sandro Carrara, Mauro Giorcelli, Alberto Tagliaferro, and Giovanni De Micheli
}

\begin{abstract}
Carbon nanotubes (CNTs) improve the sensitivity of electrochemical biosensors. An optimized CNT/trasducer integration is required to realize accurate devices. The nanotube orientation on the sensor electrode is a key parameter. The role of the sidewalls and the tips in the electroactivity of the nanosensor is presently investigated in the literature. In addition, nanotube hydrophobicity is a drawback for biosensing purposes. Indeed, samples are always in water conditions and the integration biomacromolecules-CNTs are often required. In this paper, a comparison of CNTs with and without exposed walls before and after an acid treatment is proposed. It is done by using contact angle measurements and electrochemical measurements of the electroactive compound potassium ferricyanide. Finally, the electrochemistry of two biomolecules is investigated with those nanostructures more suitable for biodetection.
\end{abstract}

Index Terms-Chemical vapor deposition, cyclic voltammetry, electrochemical biosensors, etoposide, hydrogen peroxide, multiwalled carbon nanotubes, potassium ferricyanide, wettability.

\section{INTRODUCTION}

$\mathbf{R}$ ECENTLY, nanostructures are of great interest in nanoscale engineering and system integration of existing materials for a variety of applications. Nanomaterials have enabled the development of very sensitive devices because of their excellent electronic and electrocatalytic properties leading to novel sensors with excellent characteristics. In particular, nanostructures for biosensors lead to an enhanced signal amplification and electron-transfer kinetics providing suitable environments for the immobilization of biomolecules as well as an efficient electrical communication with redox biomolecules/enzymes that may address future diagnostic needs.

Among different biosensors, those based on amperometric transducers confer a high sensitivity [1]. In this case, the signal detection involves a redox process at the electrode/solution interface between biomolecules and the transducer. Biocompounds can be detected by a transducer with an immobilized enzyme (e.g. oxidases) or oxidize and reduce spontaneously

Manuscript received December 7, 2011; revised February 23, 2012; accepted April 10, 2012. Date of publication May 4, 2012; date of current version October 15, 2012. This work was supported in part by the i-IronIC Project, and in part by LATEMAR, Centre of Excellence, funded by the Italian Ministry for Education, Universities and Research. The associate editor coordinating the review of this paper and approving it for publication was Prof. Weileun Fang.

I. Taurino, S. Carrara, and G. De Micheli are with École Polytechnique Fédérale de Lausanne, Lausanne 1015, Switzerland (e-mail: irene.taurino@epfl.ch; sandro.carrara@epfl.ch; giovanni.demicheli@epfl.ch).

M. Giorcelli and A. Tagliaferro are with the Department of Physics, Politecnico di Torino, Torino 10129, Italy (e-mail: mauro.giorcelli@polito.it; alberto.tagliaferro@polito.it).

Color versions of one or more of the figures in this paper are available online at http://ieeexplore.ieee.org.

Digital Object Identifier 10.1109/JSEN.2012.2196036 at specific potentials (e.g. etoposide, anti-breast-cancer drug [2], [3]). Nanomaterials integrated onto these electrochemical devices can improve the biomolecular detection.

Among common nanostructures, carbon nanotubes (CNTs) have attracted a large interest [4]. Non nano-structured electrodes provide good sensitivity only in millimolar $(\mathrm{mM})$ ranges [5] while nanostructured electrodes using multi walled CNTs (MWCNTs) reach detection limits in the micromolar $(\mu \mathrm{M})$ range, that is the physiological concentration range of target metabolites in human serum [6]. However, these advantages are limited by the characteristic CNT hydrophobicity [7]. CNTs tend to aggregate in many solvents producing also difficulties for bioapplications as the integration CNT-enzymes [8].

The electrochemical performance of CNT-based electrodes depends on many factors, such as the synthesis methods [9], surface treatments [10], bonding to the substrate [4], [11], orientation of tubes and type of targets [12]. Most of the literature on CNTs is based on the assumption that the tips are responsible for the good electrochemical activity [13]. The role of the sidewall is currently under investigation [12], [14]. Recent studies demonstrate a large contribution from the sidewalls in case of RO CNTs [14], [15]. The electrochemical properties of this material change by generating alterations on the CNT sidewalls [14], [16].

The aim of this work is to improve the biosensing performance of CNT-based biodevices by investigating wettability and electrochemical behavior of MWCNTs with different orientations. MWCNTs were fabricated via chemical vapor deposition (CVD) directly onto silicon wafers using camphor and ferrocene as precursors. Contact angle measurements demonstrate the effects of the treatment. Field-emission scanning electron microscopy (FE-SEM) images were acquired to observe possible morphological changes related to the treatment. Electrochemical studies were performed by using cyclic voltammetry $(\mathrm{CV})$. Potassium ferricyanide $\left(\mathrm{K}_{4} \mathrm{Fe}(\mathrm{CN})_{6}\right)$ was selected because it is a redox model compound. It was used to compare the electrochemistry of MWCNTs with and without exposed sidewalls before and after the acid treatment. Then, $\mathrm{H}_{2} \mathrm{O}_{2}$ and etoposside electrochemistry was evaluated because both these molecules have a large importance in biomedical applications.

\section{Materials AND Methods}

\section{A. Fabrication of MWCNTs Onto Silicon Wafers}

MWCNTs were grown onto a silicon wafer (Si-mat, Germany) via CVD. Camphor and ferrocene were used as carbon precursor and catalyst, respectively. Commercial camphor 


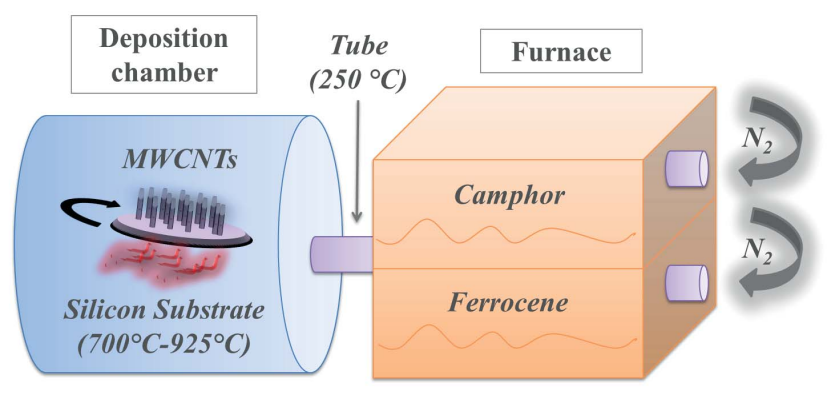

Fig. 1. Scheme of the CVD reactor for MWCNT synthesis.

was selected as the carbon precursor, since the 3D structure of this material facilitates the formation of nanotube rings [17]. Moreover, camphor is non-toxic for humans and environment [17]. Ferrocene (98\% purity in weight, Aldrich) is an organometallic chemical compound acting as both a catalyst and a carbon source. It is the source of iron atoms that agglomerate in clusters on which CNTs grow. The utilized CVD reactor consists of a furnace and of a deposition chamber connected by an heated tube $\left(250^{\circ} \mathrm{C}\right)$ to avoid the gas condensation. The furnace is fed by two evaporation chambers where the precursors are heated. In the deposition chamber, the silicon substrate is placed on a graphite plate and is heated up at the desired temperature $\left(700^{\circ} \mathrm{C}-925^{\circ} \mathrm{C}\right)$. The structure of the reactor is shown in Fig. 1. After the deposition, the substrate is cooled to room temperature inside the chamber in inert atmosphere. By varying the deposition conditions different structures can be obtained.

1) To obtain randomly-oriented MWCNTs (RO MWCNTs), the substrate is heated at $700^{\circ} \mathrm{C}$. Ferrocene is introduced in the deposition chamber for 1 minute and, at the same time, camphor is carried for 10 minutes both without gas carrier. The substrate holder rotates at $3 \mathrm{r} / \mathrm{min}$.

2) Vertically-packed MWCNTs (VP MWCNTs) are obtained with ferrocene introduction of 3 minutes. Ferrocene is carried in the deposition chamber by a laminar flow of nitrogen $\left(50 \mathrm{~cm}^{3} / \mathrm{s}\right)$. Camphor is flown for 10 minutes with no carrier gas. The substrate is kept at $850^{\circ} \mathrm{C}$ and its holder rotates at $12 \mathrm{r} / \mathrm{min}$.

3) Vertically-aligned MWCNTs with oriented tilted tips (OTT MWCNTs) are grown with a substrate temperature of $775^{\circ} \mathrm{C}$ and a rotational velocity of the silicon wafer of $40 \mathrm{r} / \mathrm{min}$. Ferrocene is introduced in the deposition chamber for 3 minutes and, then, camphor is carried for 7 minutes both with carrier gas.

\section{B. Chemicals}

All solutions were prepared using 0.01 M Phosphate Buffer Saline (PBS, Sigma) at $\mathrm{pH}$ 7.4. Pristine MWCNTs were treated in $6 \mathrm{M} \mathrm{H}_{2} \mathrm{SO}_{4}$ (Sigma, 95-98\% vol) solution for 6 hours [18]. Potassium ferricyanide in form of powder and hydrogen peroxide (30\% vol) from Sigma were utilized.

\section{Electrochemical Measurements}

$\mathrm{CV}$ was performed using a Versastat 3 potentiostat (Princeton Applied Technologies) and an electrochemical cell with a standard three electrode configuration. A platinum wire served as counter electrode, while a wire in $\mathrm{Ag} \mid \mathrm{AgCl}$ saturated with $\mathrm{KCl}(3 \mathrm{M})$ was used as reference electrode (Roschi Rohde and Schwarz AG, Switzerland). MWCNTs on silicon substrates were utilized as working electrode. All experiments were carried out under aerobic conditions at room temperature with PBS as supporting electrolyte.

From time to time, the basics of any electroanalytical techniques are explained by using electroactive species. $\mathrm{K}_{4} \mathrm{Fe}(\mathrm{CN})_{6}$ is often taken as reference analyte to decribe the fundamentals of the CV [19]. In this study, cyclic voltammograms were taken in solutions containing different concentrations of $\mathrm{K}_{4} \mathrm{Fe}(\mathrm{CN})_{6}$. This compound was selected since it is widely used for the electrochemical characterization of electrodes [20]. At carbon materials this redox couple shows a simple and well-defined response. This response is strongly dependent on the way to fabricate carbon electrodes since $\mathrm{K}_{4} \mathrm{Fe}(\mathrm{CN})_{6}$ is a "surface sensitive" compound [21]. In particular, the electrochemical investigation of new CNT-based electrodes with $\mathrm{K}_{4} \mathrm{Fe}(\mathrm{CN})_{6}$ is largely present in literature [22], [23]. The $\mathrm{K}_{4} \mathrm{Fe}(\mathrm{CN})_{6}$ redox reaction at $+300 \mathrm{mV}$ is

$$
\left[\mathrm{Fe}(\mathrm{CN})_{6}\right]^{-3}+e^{-} \rightarrow\left[\mathrm{Fe}(\mathrm{CN})_{6}\right]^{-4} \text {. }
$$

For each $\mathrm{CV}$, a linear fit of the voltammogram portion located before the start of the $\mathrm{K}_{4} \mathrm{Fe}(\mathrm{CN})_{6}$ electrochemical activity was performed. The anodic peak current $\left(I_{p a}\right)$ was taken from the baseline of the CV according to the well-known procedure [24], [25] (see Fig. 2(a) and (b)).

The Rangles-Servic equation (valid for a reversible reaction and standard temperature) was utilized to compute the electrosensing parameters [25]

$$
I_{p}=2.69 \cdot 10^{2} A D^{1 / 2} n^{3 / 2} v^{1 / 2} C
$$

where $I_{p}$ is the current peak, $A$ is the electroactive area, $D$ is the diffusion coefficient of the analyte, $n$ is the number of electrons involved in the redox reaction, $v$ is the scan rate, and $C$ is the concentration of the analyte in solution. In particular, $\left[\mathrm{Fe}(\mathrm{CN})_{6}\right]^{-3} /\left[\mathrm{Fe}(\mathrm{CN})_{6}\right]^{-4}$ couple exhibits one-electron transfer $(n=1)$. The diffusion coefficient $D$ is $5.5 \cdot 10^{-6} \mathrm{~cm} \mathrm{~s}^{-2}$.

Considering the before mentioned expression, the sensitivity per electrode area was computed in reference to the IUPAC protocol [26] from the angular coefficient of the straight line related to the calibration curve. This curve was obtained by plotting the anodic peak currents per electrode area versus the concentration of each compound in solution [4]. On the other hand, the smallest detectable current signal was taken as the mean square root deviation of the voltammogram line where no electrochemical analyte activity was observed (Fig. 2(b)). The detection limit (LOD) was computed as three times the signal-to-noise ratio according to the expression $3 \delta \mathrm{i} / \mathrm{S}$ where $\delta \mathrm{i}$ is the smallest detectable current signal related to the measurements performed for different target concentrations [27].

In reference to $\mathrm{K}_{4} \mathrm{Fe}(\mathrm{CN})_{6}$ voltammograms, ratios between the electroactive and real area and sensitivities were evaluated. The first parameter was obtained from the slope of anodic peak $\left(I_{p a}\right)$ versus the square root of the scan rate $(\sqrt{v})$ from $25 \mathrm{mV} / \mathrm{s}$ to $200 \mathrm{mV} / \mathrm{s}$ based on the expression 2 [25]. The analyte concentration was $25 \mathrm{mM}$ for VP and $2.5 \mathrm{mM}$ for RO 


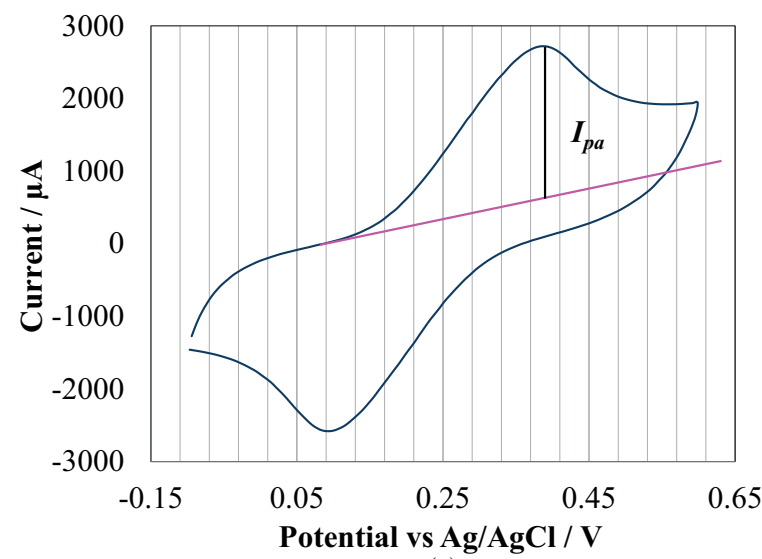

(a)

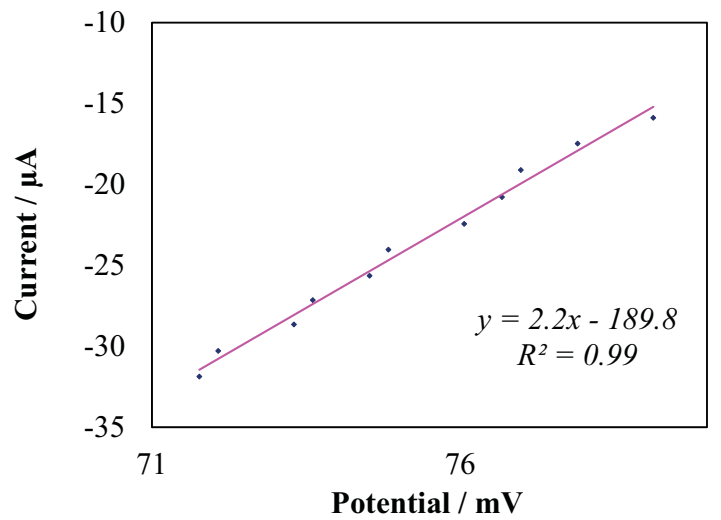

(b)

Fig. 2. Voltammogram registered with $25 \mathrm{mM} \mathrm{K}_{4} \mathrm{Fe}(\mathrm{CN})_{6}$ solution at a scan rate of $100 \mathrm{mV} / \mathrm{s}$. No significant analyte oxidation occurs between 72 and $80 \mathrm{mV}$. (a) Pink line shows the anodic baseline current obtained from a linear fit in this potential window. (b) Linear fit of the data points in the potential range $72-80 \mathrm{mV}$ shows a nearly perfect linear dependence $\left(R^{2}=0.99\right)$.

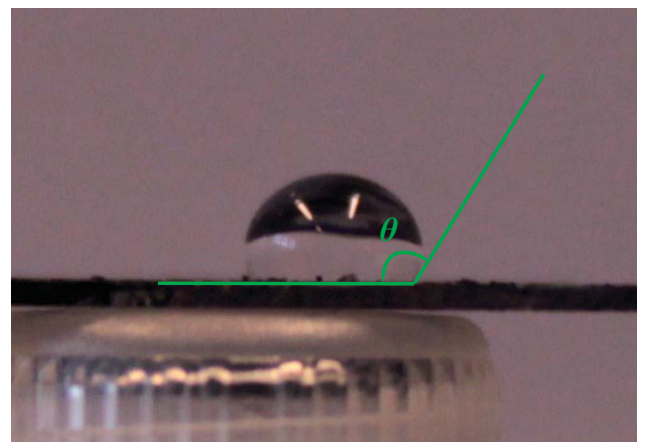

Fig. 3. Procedure used for the contact angle measurements.

MWCNTs. The sensitivity was computed with $\mathrm{K}_{4} \mathrm{Fe}(\mathrm{CN})_{6}$ concentrations in the range $2.5-15 \mathrm{mM}$ at a scan rate of $100 \mathrm{mV} / \mathrm{s}$. The potential was cycled between $-0.3 \mathrm{~V}$ and $+0.7 \mathrm{~V}$ for RO MWCNTs, and from $-0.2 \mathrm{~V}$ to $+0.6 \mathrm{~V}$ for VP nanotubes.

Voltammograms were also recorded in solutions with different concentrations of $\mathrm{H}_{2} \mathrm{O}_{2}$ that was selected for the importance of this compound in biosensing applications [28]. A potential of $+650 \mathrm{mV}$ causes the oxidation of $\mathrm{H}_{2} \mathrm{O}_{2}$, according to the reaction

$$
2 \mathrm{H}_{2} \mathrm{O}_{2} \rightarrow 2 \mathrm{H}_{2} \mathrm{O}+\mathrm{O}_{2}^{+}+4 e^{-} \text {. }
$$

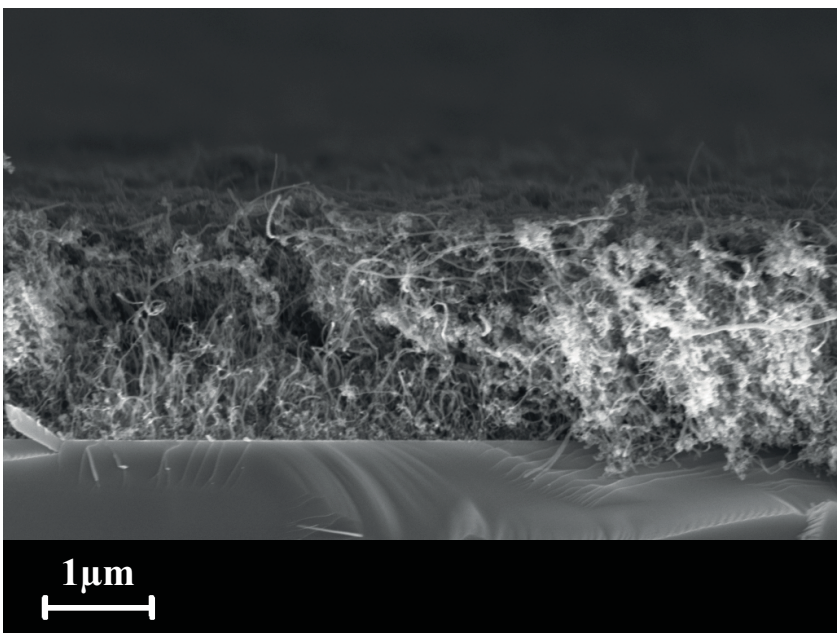

(a)

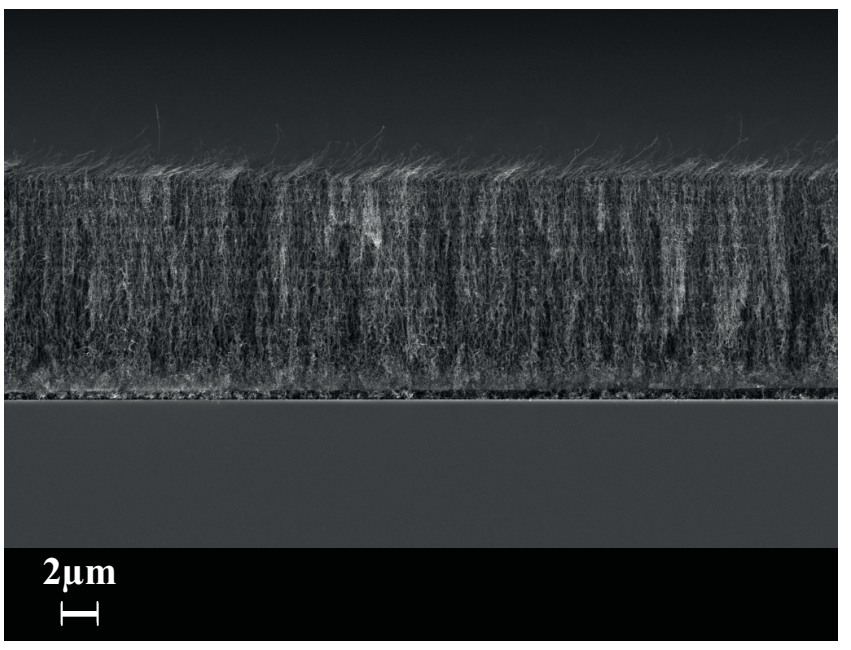

(b)

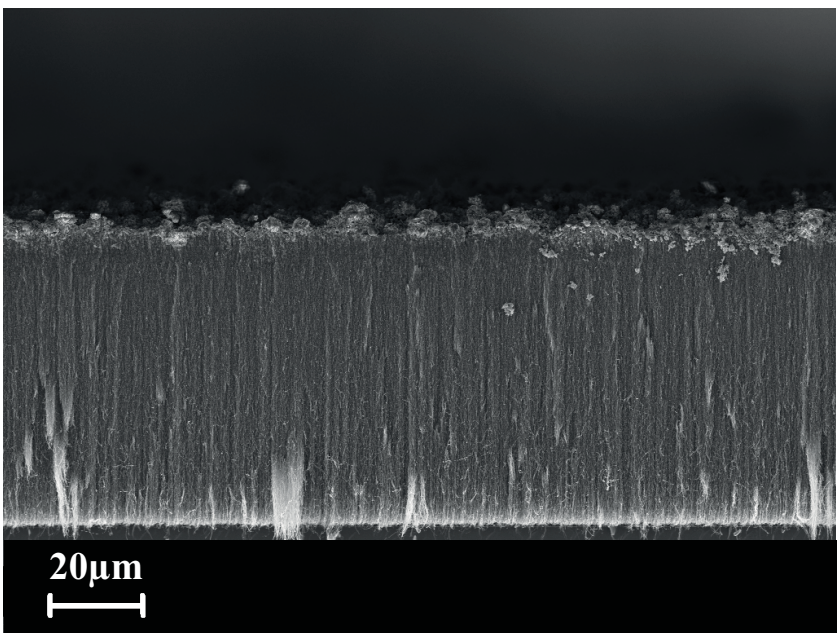

(c)

Fig. 4. (a) FE-SEM images of RO MWCNTs. (b) OTT MWCNTs. (c) VP MWCNTs.

Using hydrogen peroxide as target, concentrations were varied from 0 to $30 \mathrm{mM}$ at a scan rate of $100 \mathrm{mV} / \mathrm{s}$ to compute sensitivity and detection limit with RO CNTs before and after the treatment. The potential was cycled between $-1 \mathrm{~V}$ and $+1 \mathrm{~V}$. 
TABLE I

Contact Angle Measurements

\begin{tabular}{lc}
\hline \hline & Contact angle \\
\hline Randomly oriented MWCNTs & \\
\hline Pristine & $114^{\circ} \pm 2^{\circ}$ \\
Acid treated & $24^{\circ} \pm 9^{\circ}$ \\
\hline Vertically packed MWCNTs & \\
\hline Pristine & $109^{\circ} \pm 2^{\circ}$ \\
Acid treated & $107^{\circ} \pm 4^{\circ}$ \\
\hline MWCNTs with tilted tips & \\
\hline Pristine & $101^{\circ} \pm 7^{\circ}$ \\
Acid treated & $22^{\circ} \pm 2^{\circ}$ \\
\hline
\end{tabular}

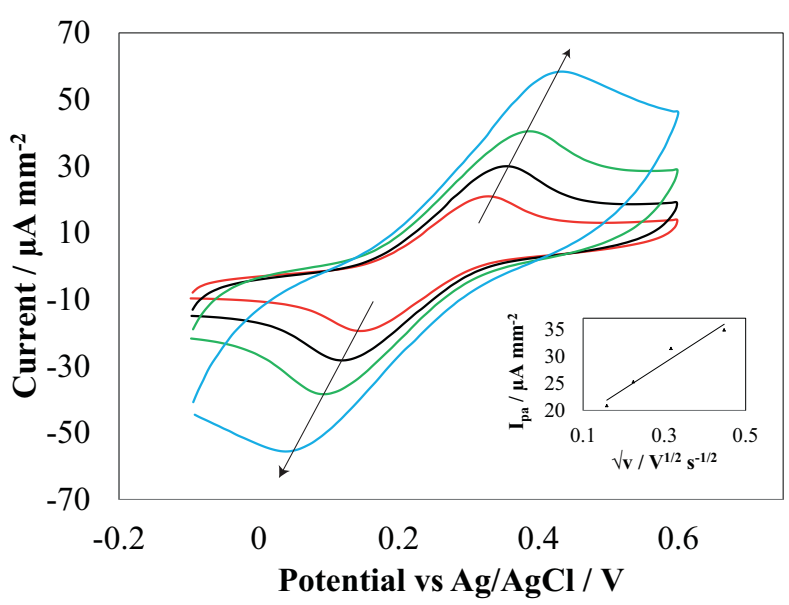

Fig. 5. Cyclic voltammograms obtained using pristine VP MWCNTs showing the effect of the scan rate on the electrochemistry of $\mathrm{K}_{4} \mathrm{Fe}(\mathrm{CN})_{6}(25 \mathrm{mM}$ in 0.01 MPBS solutions, scan rates of $25,50,100$, and $200 \mathrm{mV} / \mathrm{s}$ ). The inset shows the anodic peak currents as a function of the square root of the scan rates.

The etoposide electrolysis was carried out using treated OTT MWCNTs by varying the scan rate in the range 25-300 mV/s (analyte solution: $500 \mu \mathrm{M}$ ). To compute the sensing parameters, etoposide concentration was varied from $200 \mu \mathrm{M}$ to $500 \mu \mathrm{M}$ with steps of $100 \mu \mathrm{M}$. In reference to [3] the selected potential window was $-0.8-0.2 \mathrm{~V}$ and the scan rate was $50 \mathrm{mV} / \mathrm{s}$.

The same methods used for $\mathrm{K}_{4} \mathrm{Fe}(\mathrm{CN})_{6}$ to extract the anodic peak currents and to compute sensitivity and LOD were applied also for the study of the two probes selected for biosensing purposes.

\section{FE-SEM and Contact Angle}

A SUPRA 40 (ZEISS) was used to acquire FE-SEM images. Nominal resolution is $1.5 \mathrm{~nm}$ at $10 \mathrm{kV}$. Contact angles were measured by using PBS drops $(20 \mu \mathrm{l})$ cast onto the surface of MWCNT-based electrodes before and after the treatment. The images were acquired with a digital camera. For each sample, the average of five measurements was taken from five different images (Fig. 3).

\section{RESUlts AND Discussion}

\section{A. CNTs Fabrication}

Fig. 4 depicts the FE-SEM images obtained for RO MWCNTs, VP MWCNTs and OTT MWCNTs. RO MWCNTs

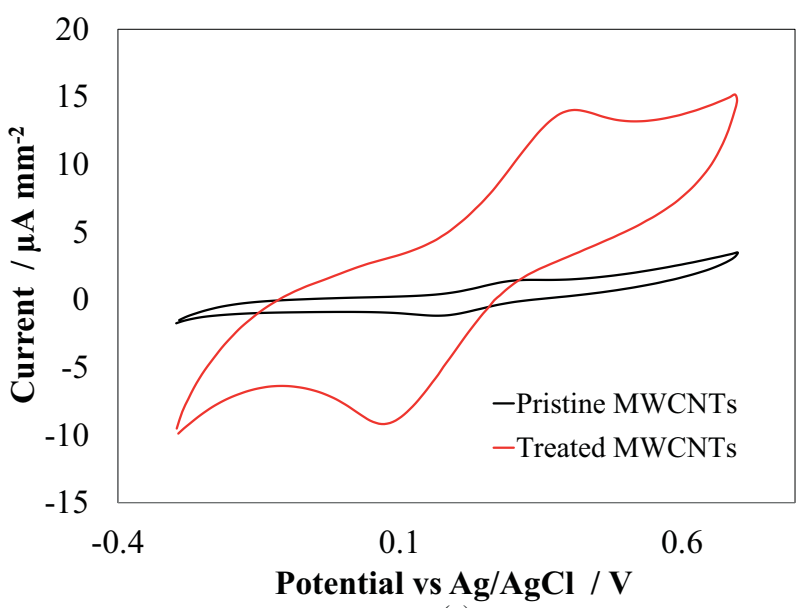

(a)

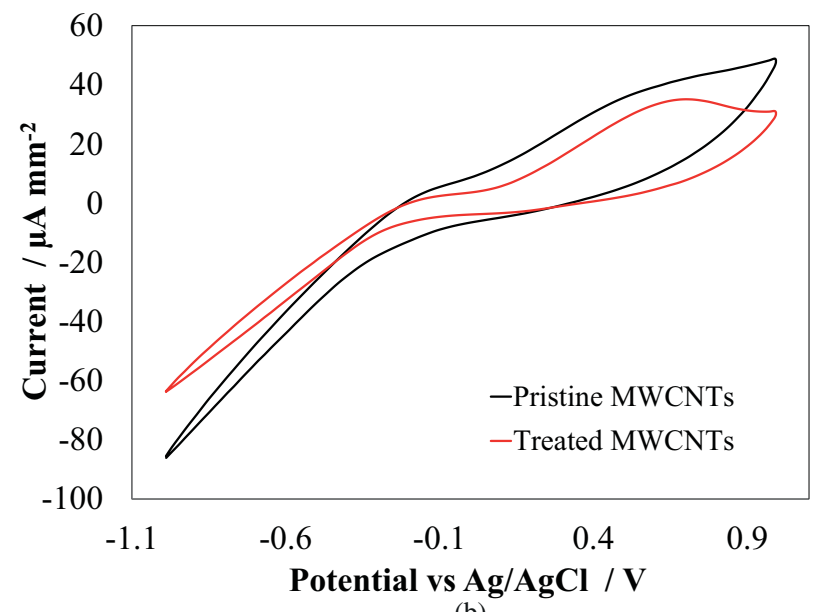

(b)

Fig. 6. (a) Cyclic voltammograms obtained with pristine and acid treated RO MWCNTs using $2.5 \mathrm{mM}$ of $\mathrm{K}_{4} \mathrm{Fe}(\mathrm{CN})_{6}$ at $25 \mathrm{mV} / \mathrm{s}$ and (b) $30 \mathrm{mM}$ of $\mathrm{H}_{2} \mathrm{O}_{2}$ at $100 \mathrm{mV} / \mathrm{s}$.

(Fig. 4(a)) are not densely packed. Both the walls and the tips of CNTs are activated with the acid treatment. OTT CNTs expose the sidewalls to the acid solution too ((Fig. 4(b)). Indeed, it is possible to note a low CNT density in the top layer of the nanofabrication that contains oriented tips (tilt angle with respect to the substrate $\simeq 30^{\circ}$ ). On the other hand, only the edge ends are subjected to the treatment when the "carpet" of VP MWCNTs are utilized (Fig. 4 (c)). FE-SEM images, taken before and after acid activation, do not show morphological changes (data not shown) demonstrating the robustness of our chip fabrications.

\section{B. Contact Angle Measurements}

Pristine MWCNTs show a hydrophobic behavior which is explained by the size and the intrinsic disorder of the tubes [7]. To investigate the effect of treatment on the three kinds of MWCNT-based electrodes, contact angles were measured. VP MWCNTs maintain a characteristic hydrophobicity (average contact angle: $107^{\circ}$ ), while RO tubes and OTT CNTs become hydrophilic after the acid treatment (average contact angle: $24^{\circ}$ and $22^{\circ}$, respectively). These results show that treated nanotubes with exposed walls are more suitable for biosensor applications. Contact angles are reported in Table I. 


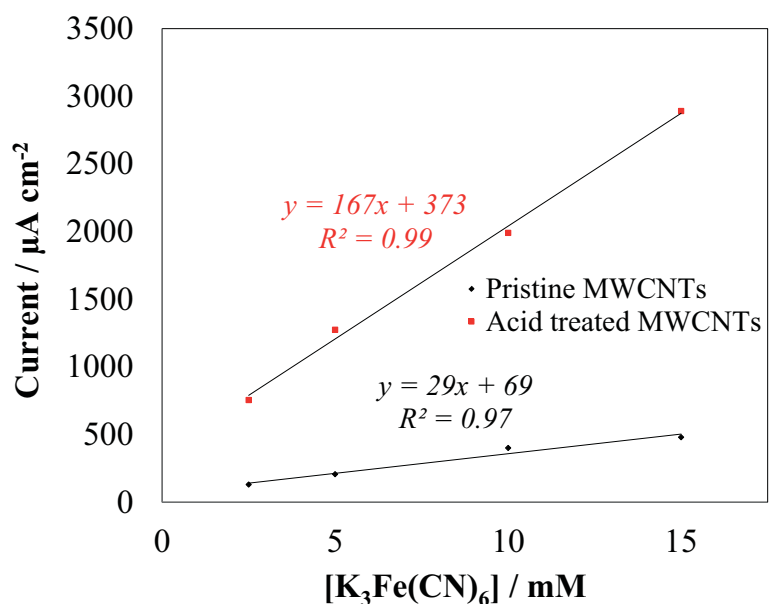

(a)

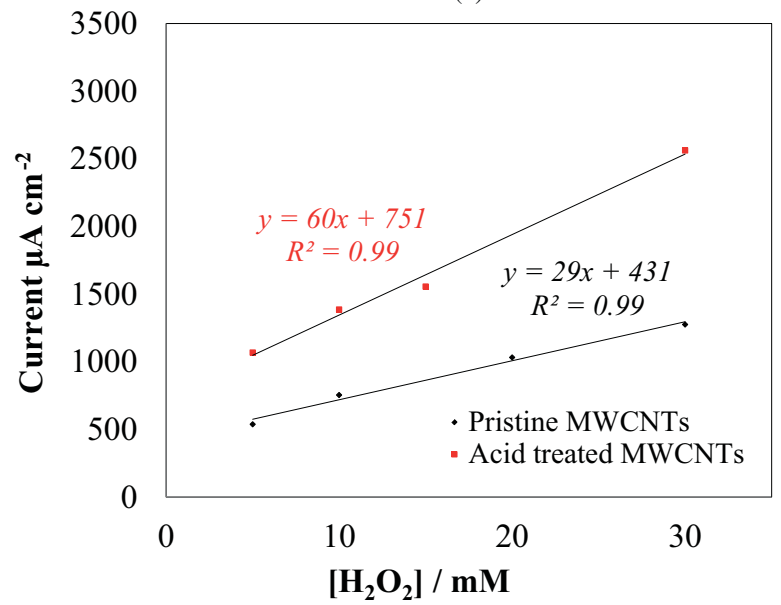

(b)

Fig. 7. (a) Calibration curves obtained using RO MWCNTs in solutions containing $\mathrm{K}_{4} \mathrm{Fe}(\mathrm{CN})_{6}$ and (b) $\mathrm{H}_{2} \mathrm{O}_{2}$ (scan rate: $100 \mathrm{mV} / \mathrm{s}$ ).

\section{Electrochemical Characterization With Potassium Ferricyanide}

The redox behavior of $\mathrm{K}_{4} \mathrm{Fe}(\mathrm{CN})_{6}$ was investigated since it is easy the extraction of the faradic currents from cyclic voltammograms. Indeed, this redox compound provides highly evident peak currents (see Fig. 5). It was done by using RO and VP MWCNTs as working electrodes before and after the treatment. For the four electrodes, CVs exhibit a pair of wellshaped redox peaks (Fig. 5) that enlarge with higher scan rate. The variation of the peak currents (example to see in the inset of Fig. 5) increases linearly with the square root of the scan rate. The peak separation is large $(>150 \mathrm{mV})$ and increases with the concentration of the analyte, indicating a high uncompensated electrode resistance [29].

From Fig. 6(a) it is possible to note a higher and more shaped peak after the acid treatment in case of RO nanotubes. These findings are confirmed by the electroactive area values. Indeed, if pristine RO MWCNTs show a ratio between electroactive area and real area of $0.227 \pm 0.005$, the value related to the acid activated tubes is one order of magnitude higher $(1.16 \pm 0.02)$ due to the introduction of sidewall active sites following the treatment. On the other hand, treatment causes a smaller increase of the electroactive/real area ratio

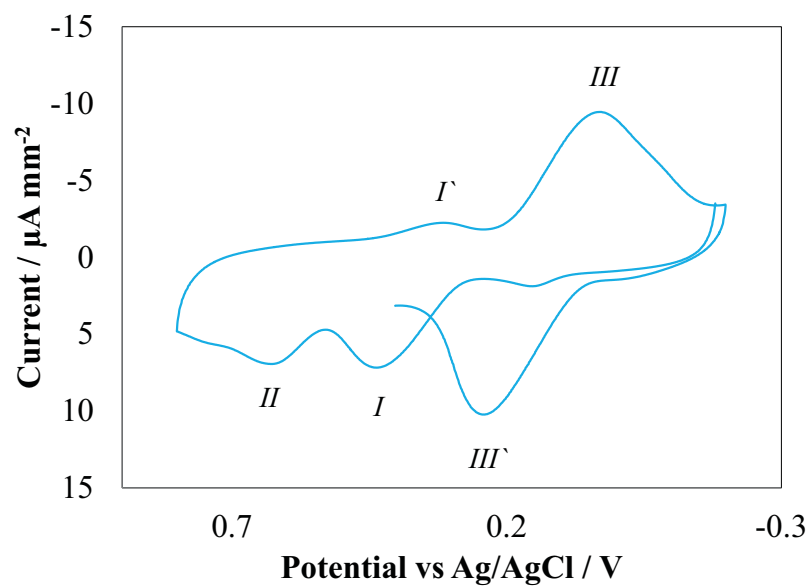

(a)

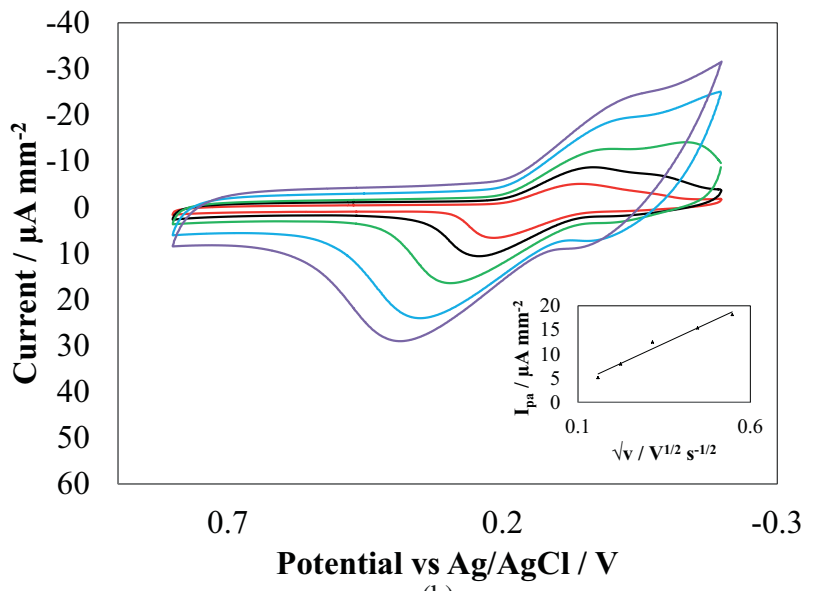

(b)

Fig. 8. (a) Cyclic voltammograms obtained using treated OTT MWCNTs showing the electrochemistry of etoposide: first cycle at a scan rate of $50 \mathrm{mV} / \mathrm{s}$ and $100 \mu \mathrm{M}$ of etoposide concentration, fifth cycle at different scan rates $(25$, $50,100,200$, and $300 \mathrm{mV} / \mathrm{s}$ ) and $500 \mu \mathrm{M}$ of etoposide concentration. (b) Inset shows the anodic peak currents as a function of the square root of the scan rates.

of about $34 \%$ (from $0.334 \pm 0.007$ to $0.506 \pm 0.010$ ) at $\mathrm{VP}$ MWCNTs. In this case, the treatment does not act on CNT sidewalls because of their low accessibility as confirmed by the wettability results (Table I).

To further validate these data, the sensitivity and the detection limit were computed. For pristine RO MWCNTs, the sensitivity is one order of magnitude smaller than for treated MWCNTs $\left(29.0 \pm 0.2 \mu \mathrm{A} /\left(\mathrm{mM} \mathrm{cm}{ }^{2}\right)\right.$ and 166.8 $\left.\pm 0.9 \mu \mathrm{A} /(\mathrm{mM} \mathrm{cm})^{2}\right)$, respectively). Instead, for pristine and treated VP MWCNTs the sensitivity remains more or less constant $\left(133.0 \pm 0.7 \mu \mathrm{A} /\left(\mathrm{mM} \mathrm{cm}^{2}\right)\right.$ and $126.5 \pm 0.7$ $\mu \mathrm{A} /\left(\mathrm{mM} \mathrm{cm}^{2}\right)$, respectively). Note that, after the treatment, the sensitivity of RO tubes becomes twice than that obtained with VP nanotubes. The detection limit does not improve with treated VP CNT-based electrode $(14.5 \pm 0.1 \mu \mathrm{M}$ for pristine and $31.8 \pm 0.2 \mu \mathrm{M}$ for treated MWCNTs). Conversely, for RO MWCNTs it goes from $188.3 \pm 1.3 \mu \mathrm{M}$ to $26.4 \pm 0.1 \mu \mathrm{M}$.

\section{Detection of Hydrogen Peroxide}

Hydrogen peroxide is also utilized as analyte because it is a product of reactions catalyzed by many enzymes, such as 
oxidases and peroxidases [28]. For the best results obtained in terms of wettability and sensing parameters towards the $\mathrm{K}_{4} \mathrm{Fe}(\mathrm{CN})_{6}$ detection, RO MWCNTs were utilized to evaluate the electrochemistry of this compound of medical interest. The peaks are well-shaped after acid treatment (see Fig. 6(b)) also using $\mathrm{H}_{2} \mathrm{O}_{2}$ in solution. The sensitivity goes from $28.8 \pm$ $0.1 \mu \mathrm{A} /\left(\mathrm{mM} \mathrm{cm}^{2}\right)$ to $59.2 \pm 0.4 \mu \mathrm{A} /\left(\mathrm{mM} \mathrm{cm}^{2}\right)$ after the treatment. The detection limit varies slightly by using acid treatment passing from from $62.1 \pm 0.4 \mu \mathrm{M}$ to $57.8 \pm 0.4 \mu \mathrm{M}$.

The different results obtained with the two probes are due to the specific electrochemical sensitivity of $\mathrm{K}_{4} \mathrm{Fe}(\mathrm{CN})_{6}$ and $\mathrm{H}_{2} \mathrm{O}_{2}$ to various surface electrode states (Fig. 7) [12]. Nonetheless, in both cases the acid activation causes an increase of the sensitivity with RO MWCNTs.

\section{E. Etoposide Electrochemistry}

The redox mechanism of the etoposide, a drug for the breast cancer treatment, was investigated as further application of biodetection. Treated OTT MWCNTs, showing the lowest average contact angle, were used as working electrode. Fig. 8 shows the etoposide common voltammogram with five characteristic peaks [3]. After the first cycle, only peaks $I I I$ and $I I I^{\prime}$ appear in the voltammogram. Fig. 8 shows the fifth cycle of multiple $\mathrm{CV}$ registered at different scan rates. Note that the peak-to-peak separation is large $(>150 \mathrm{mV})$ and expands gradually with the increase of the scan rate. The sensitivity, computed considering the anodic peak $I I I^{\prime}$ at the fifth cycle of multiple CVs, is $1.76 \pm 0.03 \mu \mathrm{A} /\left(\mathrm{mM} \mathrm{cm}^{2}\right)$ and the detection limit is $3.7 \pm 0.1 \mu \mathrm{M}$.

\section{CONCLUSION}

The goal of this paper is the evaluation of MWCNTs growth onto silicon wafers to characterize the treatment and orientation that can optimize the electrochemical biodetection. To this end, potassium ferricyanide, hydrogen peroxide and etoposide were used as target redox compounds. The first molecule was selected for its well-known electrochemical response particularly for carbon material; the latter molecules were chosen for their significant importance in biomedical applications.

The large change in wettability for RO MWCNTs and OTT nanotubes supports the assumption that acid treatment causes a predominant change on CNT sidewalls [16]. Using potassium ferricyanide, the sensitivity and the electroactive area of treated RO MWCNTs become higher than those obtained with VP MWCNTs before and after the acid activation. In addition, the detection limit is lower with treated RO CNTs. Therefore, the treatment improves the sensing parameters only in case of RO CNTs making this nanostructure more suitable for sensing purposes than VP CNTs. In particular, this nanofabrication shows a more or less unchanged electrochemical response in accordance with the contact angle data.

Considering the results related with contact angle measurements and potassium ferricyanide electrochemistry, we can argue that the CNTs with exposed sidewalls fit more properly for biosensing. Accordingly, the hydrogen peroxide and etoposide detection was performed using
CNT-based systems with sidewalls activated by acid solution. Interestingly, electrochemical responses at the electrode surface depend on the type of target. The introduction of wall electroactive groups influences more nanotube- $\mathrm{K}_{4} \mathrm{Fe}(\mathrm{CN})_{6}$ interaction rather than the interaction between MWCNTs and $\mathrm{H}_{2} \mathrm{O}_{2}$. Moreover, also the detection of hydrogen peroxide is better with treated RO MWCNTs than with pristine RO nanotubes. Finally, OTT MWCNTs have been demonstrated to be good nanostructured electrodes to investigate the direct redox reactions and the detection of the etoposide.

This work demonstrates the possibility to use MWCNTs with exposed sidewalls as nanostructures for biosensing. An acid treatment enlarges their wettability and their capability to detect electrochemical biocompounds.

\section{ACKNOWLEDGMENT}

The authors would like to thank S. Guastella to acquire FE-scanning electron microscopy images. The i-IronIC project was financed with a grant from the Swiss Nano-Tera.ch initiative and evaluated by the Swiss National Science Foundation.

\section{REFERENCES}

[1] A. Lojou and P. Bianco, "Application of the electrochemical concepts and techniques to amperometric biosensor devices," J. Electroceram., vol. 16, no. 1, pp. 79-91, 2006.

[2] A. Y. Chang, L. Hui, R. Asbury, L. Boros, G. Garrow, and J. Rubins, "Ifosfamide, carboplatin and etoposide (ICE) in metastatic and refractory breast cancer," Cancer Chemotherapy Pharmacol., vol. 44, no. 7, pp. S26-S28, 1999.

[3] J. Holthuis, W. V. Oort, F. Rmkens, J. Renema, and P. Zuman, "Electrochemistry of podophyllotoxin derivatives: Part I. Oxidation mechanism of etoposide (VP 16-213)," J. Electroanal. Chem. Int. Electrochem., vol. 184, no. 2, pp. 317-329, 1985.

[4] S. Carrara, V. Shumyantseva, A. Archakov, and B. Samorý, "Screenprinted electrodes based on carbon nanotubes and cytochromeP450scc for highly-sensitive cholesterol biosensors," Biosens. Bioelectron., vol. 24, no. 1, pp. 148-150, 2008.

[5] S. Joseph, J. Rusling, Y. Lvov, T. Friedberg, and U. Fuhr, "An amperometric biosensor with human CYP3A4 as a novel drug screening tool," Biochem. Pharmacol., vol. 65, no. 11, pp. 1817-1826, 2003.

[6] A. Cavallini, S. Carrara, V. Erokhin, and G. De Micheli, "P450-mediated electrochemical sensing of drugs in human plasma for personalized therapy," in Proc. IEEE Int. Conf. PRIME, Jul. 2010, pp. 1-4.

[7] M. Pavese, S. Musso, S. Bianco, M. Giorcelli, and N. Pugno, "An analysis of carbon nanotube structure wettability before and after oxidation treatment," J. Phys.: Condensed Matt., vol. 20, no. 47, p. 474206, Nov. 2008.

[8] K. K. Gong, Y. Yan, M. Zhang, L. Su, S. Xiong, and L. Mao, "Electrochemistry and electroanalytical applications of carbon nanotubes: A review," Anal. Sci., vol. 21, no. 12, pp. 1383-1393, 2005.

[9] M. Musameh, N. Lawrence, and J. Wang, "Electrochemical activation of carbon nanotubes," Electrochem. Commun., vol. 7, no. 1, pp. 14-18, 2005.

[10] A. Holloway, G. Wildgoose, R. Compton, L. Shao, and M. Green, "The influence of edge-plane defects and oxygen-containing surface groups on the voltammetry of acid-treated, annealed and super-annealed multiwalled carbon nanotubes," J. Solid State Electrochem., vol. 12, no. 10, pp. 1337-1348, 2008.

[11] K. Balasubramanian and M. Burghard, "Biosensors based on carbon nanotubes," Anal. Bioanal. Chem., vol. 385, no. 3, pp. 452-468, 2006.

[12] K. Gong, S. Chakrabarti, and L. Dai, "Electrochemistry at carbon nanotube electrodes: Is the nanotube tip more active than the sidewall?" Angewandte Chem. Int. Edition, vol. 47, no. 29, pp. 5446-5450, 2008.

[13] R. R. Moore, C. E. Banks, and R. G. Compton, "Basal plane pyrolytic graphite modified electrodes: Comparison of carbon nanotubes and graphite powder as electrocatalysts," Anal. Chem., vol. 76, no. 10, pp. $2677-2682,2004$ 
[14] I. Taurino, S. Carrara, M. Giorcelli, A. Tagliaferro, and G. De Micheli, "Comparing the enhanced sensing interfaces of differently oriented carbon nanotubes onto silicon for bio-chip applications," in Proc. 4th IEEE Int. Workshop Adv. Sensors Int., Jun. 2011, pp. 90-93.

[15] C. Boero, S. Carrara, G. Del Vecchio, L. Calzà, and G. De Micheli, "Highly sensitive carbon nanotube-based sensing for lactate and glucose monitoring in cell culture," IEEE Trans. Nanobiosci., vol. 10, no. 1, pp. 59-67, Mar. 2011.

[16] F. Moraes, M. Cabral, L. Mascaro, and S. Machado, "The electrochemical effect of acid functionalisation of carbon nanotubes to be used in sensors development," Surf. Sci., vol. 605, nos. 3-4, pp. 435-440, 2011.

[17] M. Kumar and Y. Ando, "Camphor-a botanical precursor producing garden of carbon nanotubes," Diamond Rel. Mater., vol. 12, nos. 10-11, pp. 1845-1850, 2003.

[18] Y. Chen, J. Huang, and C. Chuang, "Glucose biosensor based on multiwalled carbon nanotubes grown directly on Si," Carbon, vol. 47, no. 13, pp. 3106-3112, 2009.

[19] P. T. Kissinger and W. R. Heineman, "Cyclic voltammetry," J. Chem. Educ., vol. 60, no. 9, p. 702, Sep. 1983.

[20] S. Dong and J. Ding, "Electrochemical behavior of potassium ferricyanide, hydroquinone, catechol and p-aminophenol at polypyrrole film electrodes," Synth. Metals, vol. 24, no. 4, pp. 273-281, 1988.

[21] P. Chen and R. L. McCreery, "Control of electron transfer kinetics at glassy carbon electrodes by specific surface modification," Anal. Chem., vol. 68, no. 22, pp. 3958-3965, 1996.

[22] J. Wang and M. Musameh, "Carbon nanotube/teflon composite electrochemical sensors and biosensors," Anal. Chem., vol. 75, no. 9, pp. 2075-2079, 2003

[23] J. Liu, A. Chou, W. Rahmat, M. Paddon-Row, and J. Gooding, "Achieving direct electrical connection to glucose oxidase using aligned single walled carbon nanotube arrays," Electroanalysis, vol. 17, no. 1, pp. 3846, 2005.

[24] A. J. Bard and L. R. Faulkner, Electrochemical Methods: Fundamentals and Applications. New York: Wiley, 1980.

[25] S. Miserendino, J. Yoo, A. Cassell, and Y. Tai, "Electrochemical characterization of parylene-embedded carbon nanotube nanoelectrode arrays," Nanotechnology, vol. 17, no. 4, p. S23, 2006.

[26] D. Thevenot, K. Toth, R. Durst, and G. Wilson, "Electrochemical biosensors: Recommended definitions and classification," Pure Appl. Chem., vol. 71, no. 12, pp. 2333-2348, 1999.

[27] J. Mocak, A. Bond, S. Mitchell, and G. Scollary, "A statistical overview of standard (IUPAC and ACS) and new procedures for determining the limits of detection and quantification: Application to voltammetric and stripping techniques," Pure Appl. Chem., vol. 69, no. 2, pp. 297-328, 1997.

[28] C. Boero, S. Carrara, G. D. Vecchio, L. Calzà, and G. D. Micheli, "Targeting of multiple metabolites in neural cells monitored by using protein-based carbon nanotubes," Sensors Actuat. B, Chem., vol. 157, no. 1, pp. 216-224, 2011.

[29] N. Tsierkezos and U. Ritter, "Synthesis and electrochemistry of multiwalled carbon nanotube films directly attached on silica substrate," $J$. Solid State Electrochem., vol. 14, no. 6, pp. 1101-1107, 2010.

Irene Taurino received the M.Sc. degree in biomedical engineering from Politecnico di Torino, Torino, Italy, in 2010, and the M.Sc. degree in biomedical engineering from Politecnico di Milano, Milano, Italy. She carried out research for her Masters thesis at École Polytechnique Fédérale de Lausanne (EPFL), Lausanne, Switzerland. She is currently pursuing the Ph.D. degree with the Laboratory of Integrated Systems, EPFL.

She is with Politecnico di Torino, where she is working on carbon nanotube-based biosensors. Her current research interests include the development of a fully implantable enzymatic biosensor based on multiwalled carbon nanotubes to detect the human metabolites in peritoneal fluids.
Sandro Carrara is a Senior Scientist and a Lecturer with École Polytechnique Fédérale de Lausanne, Lausanne, Switzerland, and Professor of optical and electrical biosensors with the Department of Electrical Engineering and Biophysics, University of Genoa, Genoa, Italy. His current research interests include electrical phenomena of nano-bio-structured films, with special focus on protein and DNA biochips. He has published more than 100 scientific publications and holds 10 patents. He has published among the top 25 hottest articles in highly ranked international journals, such as Biosensors and Bioelectronics, Sensors and Actuators B, and Thin Solid Films in 2004, 2005, 2008, and 2009.

Prof. Carrara has been awarded several times at the NanoTera Workshop, Bern, in 2011, the IEEE International Conference PRIME with the Bronze Leaf Prize, Berlin, in 2010, the Golden Leaf Prize, Cork, in 2009, and the NanoEurope Symposium, Rapperswil, in 2009. In 2006, he was the recipient of the Best Referees' Award from Biosensor and Bioelectronics, and a NATO Advanced Research Prize in 1996 for his original contribution to the physics of single-electron conductivity in nanoparticles. He is a Founder and Editor-inChief of the journal BioNanoScience, Springer, and an Associate Editor of two IEEE TRANSACTIONS. He has been on several boards of IEEE International Conferences, mainly focused on sensors, circuits and systems for biomedical applications.

Mauro Giorcelli received the Masters degree in electrical engineering from Politecnico di Torino, Torino, Italy, in 2004, and the Ph.D. degree in physics in 2008. His dissertation was titled "Growth and characterization of carbon nanotubes." He carried out graphene studies with Cambridge University, Cambridge, U.K.

$\mathrm{He}$ is currently a Post-Doctoral Researcher with the Physics Department, Carbon Group, Politecnico di Torino, in the field of carbon material research and development.

Alberto Tagliaferro received the Ph.D. degree in physics from Politecnico di Torino, Torino, Italy, in 1987.

$\mathrm{He}$ is currently an Associate Professor of solid-state physics with Politecnico di Torino. He has carried out research concerning amorphous carbon and its alloys since 1990 . He has published more than 110 papers in international journals. His current research interests include carbon nanotubes, focusing on their growth and application.

Dr. Tagliaferro is currently an Editorial Board Member of Diamond and Related Materials, an international journal. He is currently the Chair of the Thin Film Division, International Union for Vacuum Science Technique and Applications.

Giovanni De Micheli received the Nuclear Engineer degree from Politecnico di Milano, Milano, Italy, in 1979, and the M.Sc. and Ph.D. degrees in electrical engineering and computer science from the University of California, Berkeley, in 1980 and 1983, respectively.

$\mathrm{He}$ is a Professor and Director of the Institute of Electrical Engineering and of the Integrated Systems Center, École Polytechnique Fédérale de Lausanne, Lausanne, Switzerland. He is the Program Leader of the NanoTerach Program. His current research interests include emerging technologies, networks on chips and 3-D integration, and heterogeneous platform design, including electrical components and biosensors, as well as in data processing of biomedical information.

Prof. De Micheli is a fellow of the Association for Computing Machinery and a member of the Academia Europea. He was the recipient of the IEEE Emanuel Piore Award in 2003, the Golden Jubilee Medal from the IEEE CAS Society in 2000, the D. Pederson Award for Best Paper in 1987, two Best Paper Awards from the Design Automation Conference in 1983 and 1993, and a Best Paper Award from DATE Conference in 2005. 